\title{
Teaching healthy behaviour knowledge in primary school physical education
}

\author{
Michael Hodges ${ }^{1}$, Pamela Hodges Kulinna ${ }^{2}$, Chong Lee ${ }^{3}$ \\ ${ }^{1}$ William Paterson University, 300 Pompton Road Wayne, New Jersey; ${ }^{2}$ Mary Lou Fulton Teachers College, Arizona State \\ University, Arizona; ${ }^{3}$ School of Nutrition and Health Promotion, Arizona State University, Arizona
}

\section{Summary}

Study aim: To determine the effectiveness of a newly designed series of fitness segments that can be used to provide healthy behaviour knowledge (HBK) for 5th grade Physical Education classes.

Materials and methods: 641 pupils from six intervention $(n=401)$ and five control $(n=240)$ schools were used. The intervention schools received a five-week intervention of 12-minute fitness segments for each class period. A cognitive test that has been shown to produce valid and reliable scores (28-questions) was used to assess pupils' HBK at pre - and post - examination. Pedometers were also used to examine physical activity levels differences. Hierarchical Linear Modeling using a two-level multilevel model was used to investigate mean changes in HBK between intervention and control groups.

Results: Pupils in the intervention classes had 0.8-unit greater mean improvements in HBK than did control pupils $(p<0.05)$. Girls also had greater mean changes in HBK than did boys $(p<0.05)$. There was no statistical difference between intervention and control groups in physical activity levels.

Conclusions: This type of fitness segment can be one strategy used by teachers to aid the instruction of HBK without decreasing physical activity participation in classes.

Keywords: Fitness - Strategies - PE metrics - Effectiveness - Primary

\section{Introduction}

A large percentage of children and adolescent around the globe are not achieving the recommended health sustaining activity levels $[1,3,5]$. According to the U.S. Centers of Disease Control and Prevention [3], approximately $23 \%$ of children, aged 9 through 13 , do not engage in any free time physical activity. In Australia, only approximately 31 percent of surveyed boys and girls aged 9 through 16 met the National Physical Activity Recommendations by accumulating at least 60 minutes of moderate to vigorous physical activity on most of the days surveyed [1]. Similarly, according to the 2009-2010 Healthy Behaviour in School-aged Children, one-in-five children in the European Union reported that they undergone moderate-to-vigorous exercises regularly [5]. In the U.S., many public and private school have cut in-school physical activity opportunities (e.g., recess, Physical Education), for more time on academic achievement [28], resulting in pupils having more difficulty reaching the recommended 60 minutes a day of activity. In fact, in the U.S., it was found from a School Health and Policies Study [25] that only 13.7\% of primary schools, $15.2 \%$ of middle schools, and $3.0 \%$ of high schools provided Physical Education for at least 3 days a week or equivalent, for the entire school year. Therefore, when pupils are engaging in Physical Education class, the time should be highly active and effective as possible.

\section{Pupils' Healthy Behaviour Knowledge}

Physical Education classes should be teaching the whole child. As National Association of Sport and Physical Education [20] in the U.S. states, Physical Education programs are to develop physically literate individuals who possess the knowledge, skills, and self-confidence to participate in activity for a lifetime. Numerous studies have shown that pupils do not have the requisite healthy behaviour knowledge needed to adopt healthy behaviours $[7,11,13,16]$. Healthy behaviour knowledge encompasses the necessary knowledge needed for individuals to live a lifetime of activity [31]. Kulinna et al. [15] examined this issue in a primary school setting with the use of health-related knowledge portfolio tasks. The authors discovered that more than $50 \%$ of the 3 rd to 6 th grade pupils were unable to list four aerobic and anaerobic physical 
activities. Brusseau, Kulinna, and Cothran [2] further examined primary school pupils' knowledge using portfolio tasks with two different Native American communities. Pupils completed three to six health-related physical activity behaviour portfolio tasks and results indicated that pupils across all grade levels held many misconceptions and misunderstandings of active and health concepts. Furthermore, researchers found only $7 \%$ of third grade pupils were able to describe why physical activity was important [2]. The evidence on pupil's lack of HBK is disheartening given that these findings have been evident for almost two decades [11].

Many intervention studies have been implemented and successful in remedying school-aged pupils' fundamental lack of HBK. First, Trost et al. [30] conducted an intervention study with fourth grade pupils to increase their knowledge of physical activity concepts. Before the intervention, all pupils demonstrated little understanding of physical activity concepts as defined by researchers. After the intervention, however, pupils in the intervention group showed significantly greater knowledge when compared to the control group [30]. Palmer et al. [23] conducted a study examining pupils' knowledge and learning through an internet based health program called Healthy Hearts 4 Kids which consisted of information regarding cardiovascular function, physical activity, nutrition, and tobacco. This program aimed to increase 5th grade pupils' knowledge about heart health. Palmer et al. [23] found that pupils' health knowledge was significantly increased along with an increase in positive attitudes toward physical activity attributed to the online health knowledge intervention program.

Two other notable intervention programs occurred in the U.S., these two programs called Child and Adolescent Trial for Cardiovascular health $(\mathrm{CATCH})$ and Go for Health, focused on increasing pupil knowledge and physical activity during school hours [12]. The CATCH intervention was implemented in four major U.S. cities and consisted of 96 elementary schools. The authors were able to successfully increase students' average time spent in MVPA from $37.4 \%$ to $51.9 \%$ during physical education classes [17], and marginally significant increase in knowledge [14]. Nationally this has caught some attention with the Let's Move initiative, launched by the Michelle Obama, which has one step that proposes schools to become more healthy, and incorporate nutrition education in physical education.

Curricular models were also been devised to aid the instruction of HBK and activity levels among pupils, such as, Health Optimizing Physical Education [22], Sport Play and Active Recreation for Kids [21], and the Fitness for Life [4]. The only downside to these intervention studies and curricular models is that physical activity and HBK are often taught independently of each other, and not effectively accomplished concurrently in the Physical Education classrooms.

Spiegel and Foulk [27] suggest that knowledge of physical activity and health behaviours can be the foundation that encourages people to engage in more physical activity throughout their lifetimes. This was found to contain some validity as other researchers have found individuals engaging in more activity during leisure time hours when obtaining more healthy behaviour knowledge $[6,8,29]$. Dilorenzo, Stucky-Ropp, Vander Wal, and Gotham found support for this statement, when they assembled a longitudinal study on primary pupils. Dilorenzo et al. [8] discovered that exercise knowledge was one of a few key determinants to pupils' physical activity participation. Furthermore, conceptual based Physical Education (CPE), a model that teaches health knowledge in the classroom, was also been found to positively influence physical activity patterns during leisure time [6]. More specifically, Dale, Corbin, and Cuddihy [6] reported that after a yearlong program, secondary pupils significantly increased their physical activity levels as compared to pupils with traditional Physical Education classes and control pupils. Therefore, one can venture to say there is a possibility that health knowledge has an effect on a person's decision to engage in physical activity.

Based on the lack of HBK instruction in Physical Education programs, the low documented levels of HBK among pupils, and the possible increase in physical activity during leisure time hours caused by HBK acquisition, a method that successfully increases HBK instruction without decreasing physical activity in the classroom would be invaluable. Therefore, in this intervention study, we investigated a newly developed method for teaching HBK during regular Physical Education lessons. We specifically examined the effectiveness of the method by observing: (a) if the method designed significantly increased HBK, and (b) by examining the effects, if any, on pupils' physical activity levels (with the hypothesis of no change).

\section{Materials and methods}

This study had two groups, an intervention group that received the HBK instructional lessons and a control group that did not alter their already existing curriculum and instruction.

\section{Participants}

Teachers were recruited via email from one school district. All Physical Education teachers at the fifth grade level ( 2 females and 5 males; 6 Caucasian, and 1 Hispanic) agreed to participate. Six out of the seven teachers were traveling to two schools providing a unique study design of having each teacher serve as the instructor for 
both the intervention group as well as the control group (thus taking out the teacher influence across conditions). These instructors possessed similar qualifications as they received a degree and endorsed in Physical Education. Seven-hundred and eighty 5 th grade pupils (49.9\% female and 50.1\% male; $50.8 \%$ Caucasian, $22.1 \%$ Native American, 10.6\% Hispanic, 8.9\% African American, 6.8\% Asian American, and .8\% Arab American) participated and were examined.

\section{Settings}

All participating schools (6 intervention and 5 control schools) were located in the same school district in a suburban Southwestern USA community. The school districts' Physical Education requirements for pupils were one class a week for 40 minutes. All materials (e.g., signs, equipment, lesson plans, and example of videos of the fitness segments) were provided to the teachers four days before the start of each lesson. One day of teacher training occurred before the start of the study, informing teachers about how to conduct and answer any questions on the fitness segments

The participating school district had an average free and reduced lunch percentage of $29.19 \%$ for the entire district. The Physical Education department had adopted the Dynamic Physical Education curriculum model [24]. This multi-activity curricular model includes a four-part lesson comprising: introductory activity, fitness activity, lesson focus, and game. The intervention group teachers replaced their regular fitness component with the Healthy Behaviour Fitness Segments (HBFS). The study was approved by the University, School District, and teachers, parents and pupils.

\section{Healthy Behaviour Fitness Segments}

The healthy behaviour fitness segments (HBFS) were designed to incorporate large amounts of physical activity while instilling HBK instruction. See Table 1 for a complete description of activities and the concepts emphasized in each.

Grounded in Cognitive Mediation Theory, researchers designed activities for primary pupils that integrate HBK during physical activity participation in classes. Cognitive Mediation Theory shares similarities with many other critical theories, such as constructivism and post structuralism, which view the learner as functioning and directly causing learning [26]. Rather than expecting learning to happen, the researchers developed a series of fitness segments with the goal of creating an environment that encourages pupils to think and act in ways that facilitate and apply new ideas to previous learning.

Physical Education teachers were instructed to implement the HBFS within their regular class period at their intervention school (of the two schools for each teacher, one school was randomly selected and assigned as the intervention school). Each HBFS was expected to last approximately 12 minutes and serve as the fitness portion of the lesson.

The HBFS consists of four pupil-centered activities organized into four stations. Each activity was set to last no more than 1 minute and 45 seconds. Teachers were asked to provide a brief checking for understanding segment during the brief 15-second transition from each activity. Participants were encouraged to have pre-recorded music to play during the 1 minute and 45 seconds of activity and to be silent during 15 seconds of transitions. This was intended to serve as a guide for teachers, ensuring uniformity.

Table 1. Description and objectives of the healthy behaviour knowledge fitness segments

1. Scavenger Hunt: Partners read the map (task card) given and perform the activities as they find them laid out in a contained area (i.e., hula-hoop. Performance Descriptors: Identifies the principles (guidelines) associated with improving physical fitness.

2. Body Composition Avengers: Pupils are divided and positioned at opposing hula-hoops spaced by approximately $20 \mathrm{ft}$. The hoops contain 6 yellow (fat) and 6 red bean bags (muscle). The hula-hoop signifies a body and the objective is for Pupils to have more muscle than fat in their hoops. They are to Grab only one bean bag at a time and must place them in the hoop without tossing.

3. Taking your Heart Rate: Pupils quickly choose an activity from a selection of three different activities: (a) bowling, (b) pattern walking, and (c) agility run. Pupils switch halfway to another activity after checking the effect that activity had on their heart.

4. Benefit Surprise: Pupils grab one activity card from several that are scattered face down inside a hula-hoop. Each card has a benefit associated with health-related physical fitness. They read and perform the activity; once the activity is completed, Pupils then grab another activity and continue this process for the time allotted.

5. Roll the Dice: Pupils begin by rolling the big foam dice. If it lands on an odd number, the roller decides from either an aerobic or muscular endurance exercise. If the dice lands on an even number, the roller chooses a weight bearing or flexibility exercise. 
There were a total of five activities, which were implemented into stations and placed into five different lesson segments. Therefore, teachers used the HBFS for five class sessions and offered the pupils multiple attempts to grasp the concepts from each lesson segment.

At the control schools, teachers did not alter their instruction in any way and were expected to continue their regularly assigned lesson plans as designated by the Physical Education department.

\section{Assessment Tools}

PE Metrics. The fifth grade pupils' HBK was evaluated using the PE Metrics Standards 3 \& 4, 28-question knowledge test (e.g., "The best choice for a vigorous physical activity after school is?" with four response choices). This test has previously been shown to produce reliable and valid scores in similar populations of children [19]. A member of the research team administered this 28-question pencil and paper test to both participant pupil groups before and after the implementation period.

Pedometers. Based on instrument availability, two Physical Education teachers were randomly selected to use pedometers at their respected schools, which consisted of six, fifth grade classes ( $n=53$, intervention; $n=41$, control). All pupils in the classes were provided a pedometer, and expected to quickly put on the pedometer upon entry into the gymnasium. Once the class was completed, they would remove the pedometer and a research member recorder each pupils' step count. Pedometer data were collected beginning in the second week.

Teacher Fidelity. During the study, trained research assistants observed the PE teachers and their classes twice during the study (both intervention and control classes). Twenty-eight unannounced observations were conducted and spread evenly across the five-week intervention.

The observation instrument included seven dichotomous scale items (e.g., whether the fitness lesson segments were implemented or not, and if activities were timed appropriately) and performed by a member of the research team to examine if teachers were adhering to the intervention.

\section{Data Treatment and Analysis}

Analysis included 641 participants ( $n=401$ intervention; $n=240$ control) who were enrolled in the 5 th grade.
Excluded were those with missing either pretest or posttest assessment and informed consent forms from parents or student assent forms $(n=139)$. Descriptive statistics (Means, SD) for the study participants were calculated across intervention and control groups. General linear models, at pupil level (level-1) were used to test mean differences for pedometer steps and changes in HBK between intervention and control groups. Hierarchical linear models, at school level (level-2), were used to compare mean differences for changes in HBK between intervention and control groups after adjustment for gender. The outcome measures for pupil level (level-1) include changes in HBK (HBK $\Delta$ ) and pupil ID. The pupil level covariate is a gender and the school-level (level-2) covariate is a treatment variable (intervention vs. control). The two-level multilevel models are as follows:

Level 1:

$$
\operatorname{HBK} \Delta=\beta_{0 j}+\beta_{1 j}(\operatorname{Sex})+e_{i j}
$$

where $\mathrm{i}=1,2, \ldots$ pupils, $\mathrm{j}=1,2, \ldots$ schools.

Level 2:

$$
\beta_{0 j}=\gamma_{00}+\gamma_{01} \text { (Intervention vs. Control) }+u_{0 j} \beta_{1 \mathrm{j}}=\gamma_{10} \text {. }
$$

Full model:

$$
\begin{gathered}
\operatorname{HBK} \Delta=\gamma_{00}+\gamma_{01}(\text { Intervention vs. Control) } \\
+\gamma_{10}(\operatorname{Sex})+u_{0 j}+e_{i j}
\end{gathered}
$$

Intraclass correlation coefficients (ICC), $\rho=\tau_{00} /\left(\tau_{00}+\right.$ $\sigma^{2}$ residual), were also computed to estimate the proportion of total variance between schools, intervention, and control groups $\left(\tau_{00}=\right.$ intercept $)$. All statistical procedures were performed using SAS PROC Mixed models. All $p$-values were two-tailed, and values of less than 0.05 were considered to indicate statistical significance. All procedures were performed by Statistical Analysis Systems software (SAS Institute, Cary, NC).

\section{Results}

\section{Healthy Behaviour Knowledge}

As shown in Table 2, pupils in the intervention group

\begin{tabular}{|c|c|c|c|c|c|c|c|}
\hline \multirow[b]{2}{*}{ Variable } & \multirow[b]{2}{*}{$n$} & \multicolumn{2}{|c|}{ Intervention } & \multirow[b]{2}{*}{$n$} & \multicolumn{2}{|c|}{ Control } & \multirow{2}{*}{$p$-value } \\
\hline & & Pretest & Posttest & & Pretest & Posttest & \\
\hline \multicolumn{8}{|l|}{ HBK Scores } \\
\hline Total $(n=641)$ & 401 & $14.02 \pm 4.21$ & $16.20 \pm 4.22$ & 240 & $13.43 \pm 4.24$ & $14.76 \pm 4.63$ & 0.003 \\
\hline \multicolumn{8}{|l|}{ Pedometer steps } \\
\hline Total $(n=79)$ & 43 & $1643 \pm 400$ & & 36 & $1577 \pm 535$ & & 0.53 \\
\hline
\end{tabular}
had higher changes in HBK than did control pupils at pupil level (level-1) (HBK $\Delta: 2.2$ vs. 1.33) $(p=0.003)$. There

Table 2. Descriptive statistics ( $\overline{\mathrm{X}} \pm \mathrm{SD}$ ) for HBK scores and pedometer steps (level-1) 
Table 3. Review of intervention Pupils' scores by percentage per item

\begin{tabular}{|c|c|c|c|}
\hline 3 highest scoring items & Subcategory & Pre $\mathbf{M} \pm \mathbf{S D}$ & Post $M \pm$ SD \\
\hline $\begin{array}{l}\text { (Q2) Jane wants to do something after school to } \\
\text { help her be good on the soccer team. She should. } \\
\text { - Practice dribbling a soccer ball. }\end{array}$ & $\begin{array}{l}\text { Chooses to be physically active } \\
\text { outside of school. }\end{array}$ & $0.40 \pm 0.49$ & $0.91 \pm 0.29$ \\
\hline $\begin{array}{l}\text { (Q7) If Jane can pass a flexibility test, she is more } \\
\text { likely to. } \\
\text { - Do well in gymnastics. }\end{array}$ & $\begin{array}{l}\text { Describes characteristics of health- } \\
\text { enhancing PA physical activity. }\end{array}$ & $0.87 \pm 0.33$ & $0.89 \pm 0.31$ \\
\hline $\begin{array}{l}\text { (Q13) A good score on a health-related fitness tests } \\
\text { tells you that. } \\
\text { - You have a healthy level of fitness. }\end{array}$ & $\begin{array}{l}\text { Achieves criterion-referenced } \\
\text { standards. }\end{array}$ & $0.79 \pm 0.41$ & $0.86 \pm 0.35$ \\
\hline 3 Lowest Scoring Items & Subcategory & Pre $\mathbf{M} \pm \mathbf{S D}$ & Post $\mathrm{M} \pm \mathrm{SD}$ \\
\hline $\begin{array}{l}\text { (Q11) Softball is a good. } \\
\text { - Weight-bearing activity }\end{array}$ & $\begin{array}{l}\text { Describes characteristics of health } \\
\text { enhancing PA }\end{array}$ & $0.07 \pm 0.26$ & $0.09 \pm 0.29$ \\
\hline $\begin{array}{l}\text { (Q10) Which of the following is a weight-bearing } \\
\text { activity. } \\
\text { - Doing curl-ups. }\end{array}$ & $\begin{array}{l}\text { Describes characteristics of health } \\
\text { enhancing PA }\end{array}$ & $0.03 \pm 0.176$ & $0.15 \pm 0.36$ \\
\hline $\begin{array}{l}\text { (Q25) When you want to become stronger, you } \\
\text { should. } \\
\text { - Overload your muscles. }\end{array}$ & $\begin{array}{l}\text { Identifies the principles (guidelines) } \\
\text { associated with improving physical } \\
\text { fitness }\end{array}$ & $0.16 \pm 0.37$ & $0.16 \pm 0.37$ \\
\hline
\end{tabular}

was no statistical difference in pedometer steps between intervention and control groups. Many pupils underperformed in specified items from the PE metrics (see Table 3). After reviewing the test items, question 10 and question 11 were the most commonly missed with only $10 \%$ of pupils correctly answering the questions at post-test. This was a slight increase from the pretest by $2 \%$. Estimated effects of HBFS on changes in HBK in the 5th grade pupils are presented in Table 4 (school level, level-2). Pupils with HBFS intervention had greater mean improvements in HBK than did pupils with control after adjustment for gender $(p<0.05)$. Girls had 0.55 -unit greater changes in HBK (2.00 vs. 1.45$)$ compared with boys $(p<0.05)$. There was no statistical difference in a cross-level interaction between gender and treatment.

Figure 1 shows the Tukey-Kramer post-hoc tests for changes in HBK between intervention and control groups. Changes in HBK for intervention and control groups are 2.13 and 1.33 , respectively. Pupils in the intervention group had 0.8 greater changes in HBK than did pupils in the control group $(p<0.05)$. The intraclass correlation coefficient (ICC) for schools is 0.007 indicated that approximately $0.7 \%$ of the total observed variance in changes in HBK was explained by school mean differences. There were minimal differences in variance among the schools.

Table 4. Estimated effects of HBFS on changes in HBK in the fifth grade Pupils (level-2).

\begin{tabular}{|c|c|c|c|}
\hline & Estimate & SE & $p$-value \\
\hline \multicolumn{4}{|l|}{ Fixed-Effect Parameter } \\
\hline Intercept $\left(\gamma_{00}\right)$ & 1.300 & 0.457 & 0.005 \\
\hline Treatment $\left(\gamma_{01}\right)$ (Int vs. Control) & 0.798 & 0.344 & 0.038 \\
\hline Gender $\left(\gamma_{10}\right)$ (Female vs. Male) & 0.546 & 0.267 & 0.042 \\
\hline \multicolumn{4}{|l|}{ Covariance Parameter } \\
\hline$\sigma_{\text {school }}^{2}\left(\tau_{00}\right)$ & 0.0815 & 0.114 & 0.239 \\
\hline$\sigma_{\text {Intervention }}^{2}$ & 10.373 & 0.737 & $<0.001$ \\
\hline$\sigma_{\text {Control }}^{2}$ & 13.683 & 1.254 & $<0.001$ \\
\hline$\sigma_{\text {Residual }}^{2}$ & 11.613 & 0.652 & $<0.001$ \\
\hline
\end{tabular}




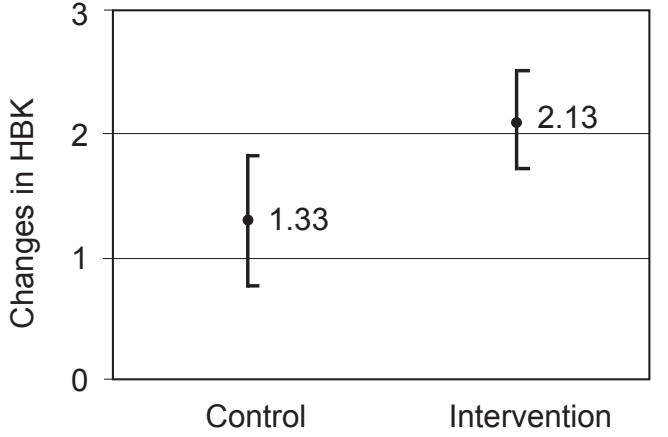

Fig. 1. Mean changes in $\mathrm{HBK}(95 \% \mathrm{CI})$ between intervention and control groups (model 2)

\section{Teacher Fidelity}

Intervention fidelity results were calculated based on data from the intervention observations. The teachers at their designated intervention school performed the proper lesson at the appropriate time, lasting no more than 15 minutes $85 \%$ of the time. At their control school Physical Education teachers were observed to provide minimal signs of HBK instruction and no signs of HBFS usage.

\section{Discussion}

Our major finding from this study was that pupils with HBFS lessons had a significant increase in HBK scores. This increase of HBK was not seen to sacrifice physical activity when compared with control pupil counterparts.

Healthy Behaviour Knowledge Improvement Strategy

The HBFS was found to provide teachers with one strategy to increase the HBK among primary pupils in Physical Education without sacrificing physical activity. Pupils at posttest scored on average 18 out of 28 on the PE Metrics exam compared to the prestest of 12 out of 28. Although the increase was slight, the results were significantly greater and significantly different then the control group pupils. Thus, this strategy will help to contribute to increasing learning and provides some progress in this area. The researchers have speculated a few reasons as to why the pupil performance on the posttest was underachieved. First, the implementation period may have been too short. The duration of the study lasted five weeks, offering pupils only five HBFS (once a week Physical Education classes). Second, the PE Metrics cognitive assessment may not be an appropriate assessment tool, as there are a wide-range of subcategories possibly making it difficult to make sense of all HBK concepts.

It was found that many concepts from the PE Metrics remained unlearned (e.g., question 10 and 11 assessed pupils' knowledge on weight bearing activities, which only showed an increase of approximately $1 \%$ at post test for the implementation group), making the assumption that this concept was simply not introduced in class.

Upon, further review of the HBFS, researchers believe additional activities that incorporate these missed concepts are necessary and would ensure a higher pupil performance on the posttest. Moreover, further studies are needed that revise the HBFS based on the current studies' findings as well as investigate a longer intervention period. Possible perceptional data on the HBFS would be beneficial, as according to the cognitive mediation theory, pupil interest is a major factor controlling the learning of novel concepts [9]. This would bring insight onto whether the HBFS was well liked and their interests had effect on pupil performance.

\section{Conclusions}

As insufficient physical activity patterns exist for youth around the world, many international organizations and World Health Organizations have called for schools and Physical Education classes to be a place for pupils to engage in high amounts of physical activity. Therefore, instructional practices that teach HBK cannot have an adverse effect on physical activity. The HBFS does not. The HBFS provides teachers with a new strategy for teaching HBK while maintaining high amounts of physical activity.

\section{References}

1. Australian National Children's Nutrition and Physical Activity Survey (2007) Children's Nutrition and Physical Activity Survey: South Australian Findings.

2. Brousseau T.A., P.H. Kulinna, D.J. Cothran (2011) Physical activity content knowledge of Native American children. The Physical Educator, 68: 66-77.

3. http://www.cdc.gov/healthyyouth/health_and_academics/pdf/pape_executive_summary.pdf

4. Corbin C.B., R. Lindsey (2006) Fitness for Life. 5th ed. Human Kinetics, Champaign.

5. Currie C., A. Zanotti, D. Morgan, M. Currie, C. deLooze, O. Roberts, O. Samdal, R.F. Smith, V. Barnekow (2012) Social determinants of health and well-being among young people. Health behaviour in school-aged children (BSC) study: International report from the 2009/2010 survey. Health Policy for Children and Adolescents, 6(1): 252.

6. Dale D., C.B. Corbin, T.F. Cuddihy (1998) Can conceptual Physical Education promote physical active lifestyles? Pediatric Exercise Science, 10: 97-109.

7. Desmond S.M, J.H. Price, R.S. Smith, D. Smith, P.W. Stewart (1990) Urban black and white adolescents' physical fitness status and perceptions of exercise. Journal of School Health, 60: 313-314. 
8. Dilorenzo T.M., R.C. Stucky-Ropp, J.S. Vander Wal, H.J. Gotham (1998) Determinants of exercise among children: A longitudinal analysis. Preventive Medicine, 27: 470-477.

9. Doyle W. (1977) Paradigms of research for teacher effectiveness. Review of Research in Education, 5: 163-198.

10. Fox K.R., S.J. Biddle (1998) The use of fitness tests: Educational and psychological considerations. Journal of Physical Education, Recreation and Dance, 59: 47-53.

11. Hopple C., G. Graham (1995) What children think, feel, and know about physical fitness testing. Journal of Teaching in Physical Education, 14: 408-417.

12. Kahn E.B., L.T. Ramsey, R.C. Brownson, G.W. Heath, E.H. Howze, K.E. Powell, P. Corso (2002) The effectiveness of interventions to increase physical activity. A systematic review. American Journal of Prevention Medicine, 22: 73-107.

13. Keating X.D., L. Chen, J. Guan, L. Harrison, B. Dauenhauer (2009) Urban minority $9^{\text {th }}$ grade pupils' health-related fitness knowledge. Research Quarterly for Exercise and Sport, 80: 747-755.

14. Kedler S., D.M. Hoelscher, C.S. Barroso, J.L. Walker, P. Cribb, S. Hu (2003) The CATCH Kids Club: A pilot after-school study for improving elementary students' nutrient and physical activity. Publich Helath Nutrition, 8: 133-140. DOI: 10.1079/PHN20004678.

15. Kulinna P.H., (2004) Physical activity and fitness knowledge: How much 1-6 grade pupils know? International Journal of Physical Education, 41: 111-121.

16. Liang M.T., H.T. Dombrowski, T.W. Allen, C.O. Chang, J. Andriulli, M. Bastianelli, S.D. Norris (1993) Do medical pupils' knowledge and attitudes about health and exercise affect their physical fitness? Journal of American Osteopathic Association, 93: 1020-1024.

17. Luepker R.V., C.L. Perry, S.M. Mckinlay, P.R. Nader, G.S. Parcel, E.J. Stone, C.C. Johnson (1996) Outcomes of a field trial to improve children's dietary patterns and physical activity. The Child and Adolescent Trial for Cardiovascular Health CATCH collaborative group. Journal of the American Medical Association, 13: 768-776.

18. National Association for Sport and Physical Education and American Heart Association (NASPE) (2012). Shape of the Nation Report: Status of Physical Education in the USA. American Alliance for Health, Physical Education, Recreation and Dance, Reston.

19. National Association of Sport and Physical Education (NASPE) (2010) PE Metrics: Assessing National Standards 1-6 in Primary School. American alliance for Health, Physical Education, Recreation and Dance, Reston.

20. National Association of Sport and Physical Education (NASPE) (2004) Moving into the Future: National
Standards for Physical Education, 2nd edition. American alliance for Health, Physical Education, Recreation and Dance, Reston.

21. Sallis J.F., T.L. McKenzie, J.E. Alcaraz, B. Kolody, N. Faucette, M.F. Hovell (1996) The effects of a 2-year Physical Education program (SPARK) on physical activity and fitness in primary school pupils. American Journal of Public Health, 87: 1328-1334.

22. Sallis J.F., T.L. McKenzie, M.W. Beets, A. Beighle, H. Erwin, S. Lee (2012) Physical Education's role in public health: Steps forward and backward over 20 years and HOPE for the future. Research Quarterly for Exercise and Sport, 83: 125-135.

23. Palmer S., G. Graham, E. Eloise (2005) Effects of a webbased health program on fifth grade children's physical activity knowledge, attitudes and behaviour. American Journal of Health Education, 36: 86-93.

24. Pangrazi R.P, A. Beighle, D. Pangrazi (2009) Promoting Physical Activity and Health in the Classroom. Benjamin Cummings Pearson, San Francisco.

25. http://www.cdc.gov/healthyyouth/shpps/2006/factsheets/ pdf/FS_PhysicalEducation_SHPPS2006.pdf.

26. Solmon M.A. (2006) Learner Cognition. In: D. Kirk, D. Macdonald and M. O'Sullivan, (eds.) Handbook of Physical Education. London, UK. SAGE Publications Ltd, pp. 226-240.

27. Spiegel S.A., D. Foulk (2006) Reducing overweight through a multidisciplinary school-based intervention. Obesity, 14: 88-96.

28. Thomas K.T. (2004) Riding to the rescue while holding on by a thread: Physical activity in the schools. Quest, 56: $150-170$.

29. Thompson A., J.C. Hannon (2012) Health-related fitness knowledge and physical activity of high school pupils. The Physical Educator, 4: 71-88.

30. Trost S.G., A.M. Morgan, R. Saunders, G. Felton, D.S. Ward, R.R. Pate (2000) Children's understanding of the concept of physical activity. Pediatric Exercise Science, 12: 293-299.

31. Zhu W., M. Safarit, A. Cohen (1999) The National HealthRelated Physical Fitness Knowledge Test: FitSmart Test User Manual (High School Edition). Champaign, Human Kinetics.

\section{Received 26.02.2014 \\ Accepted 29.05.2014}

(C) University of Physical Education, Warsaw, Poland 